\title{
Food Intake Characteristics during Early Pregnancy in Women with Gestational Diabetes Mellitus
}

\section{Atsuko Satoh ${ }^{*}$, Chikako Kishi², Sangun Lee ${ }^{3}$, Masumi Saitoh1, Miwa Miura1, Yuka Ohnuma1, Chizu Yamazaki ${ }^{1}$, Hidetada Sasaki ${ }^{4}$}

${ }^{1}$ Department of Nursing, Hirosaki University of Health and Welfare, Aomori, Japan

${ }^{2}$ Kensei Hospital, Aomori, Japan

${ }^{3}$ Department of Physical Therapy, Aomori University of Health and Welfare, Aomori, Japan

${ }^{4}$ Sendai Tomizawa Hospital, Sendai, Japan

Email: *a-satoh@jyoto-gakuen.ac.jp

How to cite this paper: Satoh, A., Kishi, C., Lee, S., Saitoh, M., Miura, M., Ohnuma, Y., Yamazaki, C. and Sasaki, H. (2017) Food Intake Characteristics during Early Pregnancy in Women with Gestational Diabetes Mellitus. Health, 9, 1711-1719. https://doi.org/10.4236/health.2017.912125

Received: October 14, 2017

Accepted: November 27, 2017

Published: November 30, 2017

Copyright $\odot 2017$ by authors and Scientific Research Publishing Inc. This work is licensed under the Creative Commons Attribution International License (CC BY 4.0).

http://creativecommons.org/licenses/by/4.0/

\begin{abstract}
To investigate the characteristic food intake during early pregnancy in women with gestational diabetes mellitus (GDM) in a rural city in Aomori Prefecture, Japan, one hundred and twenty-one women were recruited and queried about their habitual dietary intake. Food intake of patients was assessed using the model nutritional balance chart at 12 - 16, 24 - 28, and 34 - 36 weeks of gestation. Of the 121 pregnant women examined, 19 were obese. During early pregnancy, food intake ratios of the obese women were significantly lower than those of the non-obese women for the categories of milk $(\mathrm{p}<0.001)$ and sugar $(\mathrm{p}<0.05)$. GDM group was 7 women among 19 women in obesity group during mid-pregnancy. During early pregnancy, women with GDM had significantly higher sugar intake ratios than women without GDM ( $\mathrm{p}<$ 0.05). These results suggested that obese pregnant women are able to prevent GDM by limiting their sugar intake during early pregnancy.
\end{abstract}

\section{Keywords}

Gestational Diabetes Mellitus, Food Intake Characteristics, Sugar Intake, Obesity, Early Pregnancy

\section{Introduction}

Diabetes mellitus (DM) is an escalating epidemic worldwide [1]. According to the World Health Organization, the number of DM cases is projected to rise 
by $>50 \%$ by the year 2020 , if urgent interventions are followed to reverse this trend [2]. Gestational DM (GDM), a common pregnancy complication defined as glucose intolerance with onset or first recognition during pregnancy, is related to a substantially increased subsequent risk of metabolic syndrome, type 2 DM, and pregnant complications [3]. By tracking reports on DM, it appears that approximately $40 \%$ of women with GDM develop DM 20 years later [4] [5] [6]. The new worldwide GDM standard was announced by the International Association of Diabetes and Pregnancy Study Groups in 2010 [7]. The Japan Diabetes Society adopted the new standards in July 2010 [8]. In the present study, we investigated food intake characteristics of women with GDM using model nutritional balance chart (MNBC) [9].

\section{Methods}

The setting was a rural city in Aomori Prefecture, northern Japan, (population, 177,000; number of births from April 2015 to January 2016, 1140) where pregnant women were evaluated during 12 - 16 weeks of pregnancy (hereafter called early pregnancy) at two different obstetric clinics. A pregnant woman was considered obese when her body mass index (BMI) exceeded $25 \mathrm{~kg} / \mathrm{m}^{2}$; those with $\mathrm{BMI}<25 \mathrm{~kg} / \mathrm{m}^{2}$ were considered non-obese before pregnancy. We defined obesity according to the cutoff values established by the Japan Society for the Study of Obesity. All pregnant women received a 75-g oral glucose tolerance test (OGTT) to diagnose GDM at 24 - 28 weeks after pregnancy (hereafter called mid-pregnancy). The Japan Society Obstetrics and Gynecologycriteria for the diagnosis of GDM using OGTT are as follows: fasting glucose of $92 \mathrm{mg} / \mathrm{dL}, 1-\mathrm{h}$ $180 \mathrm{mg} / \mathrm{dL}$, and 2-h $153 \mathrm{mg} / \mathrm{dL}$. We identified women with one or more plasma concentrations that met or exceeded these thresholds as having GDM.

Pregnant women who agreed to participate in the study completed self-reported questionnaires. Among 138 subjects, 17 refused to participate in the study. One hundred and twenty-one subjects aged $31 \pm 5$ years completed the questionnaires during early pregnancy, and these subjects were prospectively followed up during mid-and late pregnancy (34 - 36 weeks after pregnancy). To ascertain subjects' socio-psychological states, we provided four questionnaires dealing with different aspects that contained the following questions: questionnaire 1, social status (age, educational level, and annual income); questionnaire 2, obstetric factors [previous childbirth experience (i.e., primipara or multipara)]; questionnaire 3, physical status [height and weight before pregnancy, subjects' worries about their own physical condition (good or bad), smoking habits before pregnancy, alcohol consumption before pregnancy, smoking habits of the subject's husband, height and weight of husband, excise habits before pregnancy (at least twice per week)]; and questionnaire 4, eating habits (eating or not eating breakfast, late night snacking, and nutritional balance). During mid-pregnancy, we asked each subject in the GDM and non-GDM groups to report their age, family history of DM, weight, and physical activity (at least twice per week). 
Food intake was assessed using MNBC [9].

MNBC was described previously and briefly introduced here. NMBC was designed to outline a 6697-kj intake according to the recommendations of the Ministry of Health, Labor and Welfare [10]. MNBC demonstrates the ideal dietary distribution of 11 categories of food: potatoes and grains (hereafter called grains), meat, fish, eggs, milk and dairy products (hereafter called milk), beans and bean products, such as bean curd and miso soup (hereafter called beans), green and yellow vegetables, light-colored vegetables, fruits, oils, and sugar. The number of times each food category was consumed was marked with black dots, and the foods eaten were recorded by category, but not by amount. MNBC includes foods consumed for 3 days per month. Food intake of patients was assessed using MNBC at $12-16$, (first time) $24-28$ (second time), and $34-36$ weeks (third time) of gestation. Subjects participated in the study from April 2014 to June 2015.

The intervention method consisted of three steps performed. 1) The investigator mailed the meal chart to the subjects. The meal chart consisted of columns for breakfast, lunch, dinner, and snacks between meals. The meal chart was to be filled out for 3 days of the last week of each month; subjects were instructed to record the name of each food eaten on the meal chart; 2) subjects completed a meal chart based on a 24-h recall and mailed it to the investigators; 3 ) the investigators placed black dots on the Computerized MNBC according to the content of the meal chart. Each time any food was consumed, one black dot was placed on the nutritional balance chart in the corresponding section. We compared the distribution of foods for each menu plan to the foods that were eaten. Foods cooked at home, as well as those that were commercially available, and prepared food were converted from the food exchange list published by the Japan Diabetes Society [11]. The nutritional balance chart was mailed to the subjects within 1 week after receiving the meal chart. The above steps were followed three times in early, mid-, and late pregnancies.

We calculated the nutritional balance as follows: [food intake ratio $=$ the actual food intake (black dots)/the ideal food intake following the MNBC (black dots)]. Thus, an ideal nutritional balance, based on the MNBC, was "1".

The study protocol adhered to the recommendations of the Declaration of Helsinki [12]. Verbal informed consent was obtained, and subjects' anonymity was preserved using a coding system. Ethical approval was obtained from the Ethical Committee of Hirosaki University of Health and Welfare, Japan. The statistical difference of the sociopsychological state between subjects in the obesity and non-obesity groups were calculated using a chi-squared test. Among obese subjects, statistical differences between the GDM and non-GDM group were calculated using the chi-squared test. The two-sided Mann-Whitney's U test was used to determine significant differences in the food intake ratio in early, mid-, and late pregnancies. In all items, statistical significance was considered for p-values $<0.05$. 


\section{Results}

Of the 121 pregnant women, 19 were classified as obese during early pregnancy. The average pre-pregnancy BMI of obese subjects was $28.8 \pm 3.7 \mathrm{~kg} / \mathrm{m}^{2}$ (range: 25.1 - 39.7) and the average BMI of non-obese subjects was $20.9 \pm 1.5 \mathrm{~kg} / \mathrm{m}^{2}$ (range: 16.0 - 24.0). Subjects' socio-psychological states are shown in Table 1. Husbands' obesity and the degree to which subjects cared about nutritional balance were significantly different between obese and non-obese subjects ( $\mathrm{p}<$ $0.05)$. During early pregnancy, milk $(\mathrm{p}<0.001)$ and sugar $(\mathrm{p}<0.05)$ intake ratios of obese subjects were significantly lower than those of non-obese subjects (Table 2). Of the 101 pregnant women, 19 were classified as obese during mid-pregnancy. During mid- pregnancy, grain $(\mathrm{p}<0.05)$, meat $(\mathrm{p}<0.01)$, milk $(\mathrm{p}<0.001)$, oil $(\mathrm{p}<0.05)$ and sugar $(\mathrm{p}<0.05)$ intake ratios of obese subjects were significantly lower than those of non-obese subjects (Table 2). Of the 93 pregnant women, 15 were classified as obese during late pregnancy. During late pregnancy, only milk $(\mathrm{p}<0.05)$ intake ratios of obese subjects were significantly lower than those of non-obese subjects (Table 2).

GDM group were 7 women among 19 women in obesity group during mid-pregnancy. During early pregnancy, obese subjects with GDM had significantly higher sugar intake ratios than those who did not have GDM $(\mathrm{p}<0.05)$ (Table 3).

During mid-pregnancy, there were no significant differences between subjects with and without GDM regarding family history (42\% versus $25 \%$ ) and exercise habits (0\% versus $9 \%)$. On comparing weight gain during early and mid-pregnancy, there were no between-group differences.

All women with GDM were hospitalized during mid-pregnancy and received a hospital diet. There were no significant differences in food intake ratios between subjects with and without GDM during mid-pregnancy (Table 3).

GDM group was 7 women among 15 women in obesity group during late pregnancy. There was no significant difference in food intake ratios between subjects with and without GDM during late pregnancy (Table 3).

\section{Discussion}

In this study, sugar intake ratios of $2.0 \pm 1.2$ (obese subjects) versus $2.8 \pm 1.4$ (non-obese subjects) indicated significantly higher sugar intake for non-obese subjects during early pregnancy. Reportedly, women with nausea and vomiting during pregnancy may have higher carbohydrates and added sugar intake [13]. In this study, obese subjects, aware of their diagnosis of obesity at study onset, may have refrained from excessive sugar intake.

There are many factors that can affect GDM. Age [14], pre-pregnancy BMI [15], family history of DM [16], weight gain during pregnancy [17], exercise habits [18], and nutritional habits [19] [20] [21] are all related to GDM. In this study, all subjects who developed GDM were obese. On the other hand, there were no significant differences between subjects with GDM and without GDM 
Table 1. Characteristics of subjects.

\begin{tabular}{|c|c|c|c|c|}
\hline & & Obesity & Non-obesity & p-value \\
\hline & & $\mathrm{n}=19$ & $\mathrm{n}=102$ & \\
\hline Age (years) & & $32 \pm 6$ & $31 \pm 5$ & - \\
\hline BMI $\left(\mathrm{kg} / \mathrm{m}^{2}\right)$ & & 28.8. \pm 3.7 & $20.9 \pm 1.5$ & - \\
\hline \multirow[t]{2}{*}{ Education } & High school & 9 & 48 & \multirow{2}{*}{ NS } \\
\hline & University & 10 & 54 & \\
\hline \multirow[t]{2}{*}{ Occupation } & Yes & 12 & 77 & \multirow{2}{*}{ NS } \\
\hline & No & 6 & 25 & \\
\hline \multirow[t]{3}{*}{ Annual income (million yen) } & $<300$ & 6 & 25 & \multirow{3}{*}{ NS } \\
\hline & $300-$ & 9 & 32 & \\
\hline & $500-$ & 2 & 22 & \\
\hline \multirow[t]{2}{*}{ Family structure } & Nuclear & 14 & 60 & \multirow{2}{*}{ NS } \\
\hline & Expanded & 4 & 41 & \\
\hline \multirow[t]{2}{*}{ Delivery } & Primipara & 10 & 57 & \multirow{2}{*}{ NS } \\
\hline & Multipara & 8 & 43 & \\
\hline \multirow[t]{2}{*}{ Experience of } & Yes & 9 & 28 & \multirow{2}{*}{ NS } \\
\hline & No & 9 & 74 & \\
\hline \multirow{6}{*}{ Physical condition } & Good & 5 & 29 & \multirow{2}{*}{ NS } \\
\hline & $\mathrm{Bad}$ & 14 & 73 & \\
\hline & \multicolumn{4}{|l|}{ Contents (overlapped) } \\
\hline & Morning sickness & 11 & 52 & NS \\
\hline & Constipation & 6 & 33 & NS \\
\hline & Lower back pain & 5 & 26 & NS \\
\hline Worries about & Yes & 2 & 15 & \\
\hline own physical condition & No & 17 & 82 & NS \\
\hline \multirow[t]{2}{*}{ Smoking habit before pregnancy } & Yes & 7 & 22 & \multirow{2}{*}{ NS } \\
\hline & No & 11 & 80 & \\
\hline \multirow[t]{2}{*}{ Smoking habit of husband } & Yes & 14 & 61 & \multirow{2}{*}{ NS } \\
\hline & No & 5 & 41 & \\
\hline \multirow[t]{2}{*}{ BMI $\left(\mathrm{kg} / \mathrm{m}^{2}\right)$ of husband } & $\geq 25$ & 10 & 72 & \multirow{2}{*}{ * } \\
\hline & $<25$ & 9 & 22 & \\
\hline Alcohol consumption & Yes & 13 & 64 & \multirow{2}{*}{ NS } \\
\hline before pregnancy & No & 5 & 38 & \\
\hline Exercise habit before pregnancy & Yes & 2 & 24 & \multirow{2}{*}{ NS } \\
\hline (at least twice per weeks) & No & 16 & 78 & \\
\hline Habit of considering & Yes & 11 & 81 & \multirow{2}{*}{ * } \\
\hline care about nutritional balance & No & 8 & 21 & \\
\hline
\end{tabular}

${ }^{\star} \mathrm{p}<0.05$, NS; not significant. 
Table 2. Difference of food intake ratio between obesity and non-obesity group from early to late pregnancy.

\begin{tabular}{|c|c|c|c|c|c|c|c|c|c|c|c|c|c|c|}
\hline & & & Grain & Meat & Fish & Eggs & Milk & Beans & $\begin{array}{c}\text { Green } \\
\text { and } \\
\text { yellow } \\
\text { vegetables }\end{array}$ & $\begin{array}{l}\text { Light-colored } \\
\text { vegetables }\end{array}$ & Fruit & Oil & Sugar & $\begin{array}{c}\text { Mean } \pm \\
\quad \text { SD }\end{array}$ \\
\hline \multirow{5}{*}{$\begin{array}{c}\text { Early } \\
\text { pregnancy }\end{array}$} & Obesity & Mean & 1.0 & 0.9 & 1.5 & 1.1 & 0.4 & 0.8 & 0.8 & 0.7 & 0.5 & 1.2 & 2.0 & 1.0 \\
\hline & $\mathrm{n}=19$ & SD & 0.5 & 0.5 & 1.0 & 1.0 & 0.4 & 0.5 & 0.4 & 0.2 & 0.5 & 0.6 & 1.2 & 0.4 \\
\hline & Non-obesity & Mean & 1.1 & 1.0 & 1.6 & 1.2 & 0.8 & 1.0 & 0.8 & 0.8 & 0.5 & 1.3 & 2.8 & 1.2 \\
\hline & $\mathrm{n}=102$ & SD & 0.4 & 0.5 & 1.1 & 0.6 & 0.5 & 0.7 & 0.4 & 0.3 & 0.5 & 0.6 & 1.4 & 0.4 \\
\hline & & & NS & NS & NS & NS & $* * *$ & NS & NS & NS & NS & NS & * & * \\
\hline \multirow{5}{*}{$\begin{array}{c}\text { Mid- } \\
\text { pregnancy }\end{array}$} & Obesity & Mean & 1.0 & 0.8 & 1.5 & 1.1 & 0.6 & 1.3 & 0.9 & 0.9 & 0.7 & 1.3 & 2.6 & 1.2 \\
\hline & $\mathrm{n}=19$ & SD & 0.4 & 0.3 & 1.3 & 0.5 & 0.3 & 1.0 & 0.3 & 0.3 & 0.7 & 0.5 & 1.2 & 0.6 \\
\hline & Non-obesity & Mean & 1.2 & 1.1 & 1.6 & 1.1 & 0.9 & 1.1 & 0.9 & 0.9 & 0.8 & 1.5 & 3.0 & 1.3 \\
\hline & $\mathrm{n}=82$ & SD & 0.4 & 0.5 & 0.9 & 0.5 & 0.6 & 0.7 & 0.4 & 0.6 & 0.6 & 0.5 & 1.3 & 0.6 \\
\hline & & & * & $* *$ & NS & NS & $* * *$ & NS & NS & NS & NS & * & * & NS \\
\hline \multirow{5}{*}{$\begin{array}{c}\text { Late } \\
\text { pregnancy }\end{array}$} & Obesity & Mean & 1.1 & 1.1 & 1.3 & 1.2 & 0.6 & 1.0 & 1.0 & 1.0 & 0.6 & 1.3 & 2.9 & 1.2 \\
\hline & $\mathrm{n}=15$ & SD & 0.4 & 0.3 & 0.8 & 0.5 & 0.3 & 0.5 & 0.4 & 0.3 & 0.5 & 0.4 & 0.9 & 0.3 \\
\hline & Non-obesity & Mean & 1.2 & 1.1 & 1.5 & 1.2 & 1.0 & 1.2 & 0.9 & 0.8 & 0.8 & 1.5 & 3.1 & 1.3 \\
\hline & $\mathrm{n}=78$ & SD & 0.4 & 0.4 & 0.9 & 0.6 & 0.5 & 0.7 & 0.4 & 0.3 & 0.6 & 0.5 & 1.3 & 0.6 \\
\hline & & & NS & NS & NS & NS & * & NS & NS & NS & NS & NS & NS & NS \\
\hline
\end{tabular}

Mann-Whitney's U test test; ${ }^{*} \mathrm{p}<0.05,{ }^{* *} \mathrm{p}<0.01,{ }^{* * *} \mathrm{p}<0.001, \mathrm{NS}$; not significant.

in family histories of DM, exercise habits, and weight gain from early to mid-pregnancy. After MNBC analysis, sugar emerged as the factor wherein intake ratios during early pregnancy significantly differed between obese and non-obese subjects $(\mathrm{p}<0.05)$. Sugar intake ratios were significantly higher in subjects with GDM compared than in those without GDM ( $\mathrm{p}<0.05)$. In this study, we considered that food intake conditions affect GDM and that greater sugar intake during early pregnancy may contribute to GDM onset.

Sugar-sweetened beverages are associated with an increased risk of DM [22], but sugar does not trigger DM [23]. The pathological condition of GDM is attributable to reduced insulin secretion secondary to reduced pancreatic beta cell function during pregnancy. Therefore, even if there is obesity, GDM does not occur if insulin secretion is good; GDM occurs if insulin secretion is lowered. In this study, obese pregnant women who ingested sugar more frequently during early pregnancy had increased incidence of GDM. Excessive sugar intake may have burdened insulin secretion from the pancreas. These results suggested that obese pregnant women are able to prevent GDM by limiting sugar intake during early pregnancy.

There are several limitations in the present study. First, a small number of subjects might lead to false-positive conclusion. The subjects choosing to 
Table 3. Difference of food intake ratio between Gestational diabetes mellitus (GDM) and non-GDM in obesity group.

\begin{tabular}{|c|c|c|c|c|c|c|c|c|c|c|c|c|c|c|}
\hline & & & Grain & Meat & Fish & Eggs & Milk & Beans & $\begin{array}{c}\text { Green and } \\
\text { yellow } \\
\text { vegetables }\end{array}$ & $\begin{array}{l}\text { Light-colored } \\
\text { vegetables }\end{array}$ & Fruit & Oil & Sugar & $\begin{array}{l}\text { Mean } \\
\pm \text { SD }\end{array}$ \\
\hline \multirow{5}{*}{$\begin{array}{c}\text { Early } \\
\text { pregnancy }\end{array}$} & GDM & Mean & 1.1 & 0.9 & 1.7 & 1.1 & 0.6 & 0.8 & 0.7 & 0.6 & 0.6 & 1.2 & 2.7 & 1.1 \\
\hline & $\mathrm{n}=7$ & SD & 0.4 & 0.3 & 1.0 & 0.4 & 0.4 & 0.5 & 0.4 & 0.2 & 0.6 & 0.4 & 1.0 & 0.5 \\
\hline & Non-GDM & Mean & 0.9 & 0.8 & 1.3 & 1.1 & 0.3 & 0.7 & 0.8 & 0.7 & 0.4 & 1.2 & 1.5 & 0.9 \\
\hline & $\mathrm{n}=12$ & SD & 0.5 & 0.5 & 1.0 & 1.0 & 0.2 & 0.5 & 0.4 & 0.3 & 0.4 & 0.6 & 1.2 & 0.4 \\
\hline & & & NS & NS & NS & NS & NS & NS & NS & NS & NS & NS & * & NS \\
\hline \multirow{4}{*}{$\begin{array}{c}\text { Mid- } \\
\text { pregnancy }\end{array}$} & GDM & Mean & 0.9 & 0.8 & 1.1 & 0.9 & 0.4 & 1.1 & 0.8 & 0.7 & 0.6 & 1.2 & 2.3 & 1.0 \\
\hline & $\mathrm{n}=7$ & SD & 0.4 & 0.3 & 0.9 & 0.6 & 0.3 & 0.7 & 0.3 & 0.3 & 0.6 & 0.5 & 1.1 & 0.5 \\
\hline & Non-GDM & Mean & 1.0 & 0.6 & 1.8 & 1.1 & 0.8 & 1.5 & 1.0 & 1.0 & 0.8 & 1.2 & 2.7 & 1.2 \\
\hline & $\mathrm{n}=12$ & SD & 0.4 & 0.3 & 1.5 & 0.4 & 0.3 & 1.2 & 0.3 & 0.3 & 0.7 & 0.6 & 1.1 & 0.5 \\
\hline \multirow{6}{*}{$\begin{array}{c}\text { Late } \\
\text { pregnancy }\end{array}$} & & & NS & NS & NS & NS & NS & NS & NS & NS & NS & NS & NS & NS \\
\hline & GDM & Mean & 1.0 & 0.9 & 1.3 & 1.1 & 0.7 & 1.0 & 0.8 & 1.0 & 0.5 & 1.2 & 2.7 & 1.1 \\
\hline & $\mathrm{n}=7$ & SD & 0.4 & 0.3 & 0.7 & 0.5 & 0.3 & 0.4 & 0.3 & 0.2 & 0.4 & 0.4 & 0.6 & 0.3 \\
\hline & Non-GDM & Mean & 1.1 & 1.2 & 1.3 & 1.2 & 0.6 & 1.0 & 1.1 & 0.9 & 0.8 & 1.4 & 2.9 & 1.2 \\
\hline & $\mathrm{n}=8$ & SD & 0.4 & 0.4 & 0.9 & 0.6 & 0.3 & 0.6 & 0.4 & 0.3 & 0.6 & 0.5 & 1.1 & 0.4 \\
\hline & & & NS & NS & NS & NS & NS & NS & NS & NS & NS & NS & NS & NS \\
\hline
\end{tabular}

Mann-Whitney’s U test; ${ }^{*} \mathrm{p}<0.05$, NS; not significant.

participate in the present study might bias the positive results. Second, several other personal factors may be related to GDM. For example, Thagaard et al. reported that low concentrations of adiponectin were associated with GDM in all BMI groups [24]. Finally, the participants were responsible for reporting their own food intake by category but not by the amount of food. Women with higher BMI tend to under-report intake of all foods and nutrients [25]. It is possible that subjects with higher BMI may preferentially under-report certain foods or nutrients (e.g. junk foods), which introduces a source of confounding that is difficult to account for food intake. However, health control during pregnancy is an important concern for midwives and nurses [26], and it is important for managing the health of pregnant women. Our method is a simple way to visually educate the pregnant women regarding good nutrition habit.

Obese pregnant women should receive nutritional advice from midwives or nurses during early pregnancy and throughout gestation using MNBC. Additionally, at-risk women should frequently monitor their food intake.

\section{Acknowledgements}

This work was supported by JSPS KAKENHI Grant Numbers 26463392. 


\section{Conflicts of Interest}

We declare no conflicts of interest.

\section{References}

[1] Chan, L., Magliano, D.J. and Zimmer, P.Z. (2012) The Worldwide Epidemiology of Type 2 Diabetes Mellitus-Present and Future Perspectives. Nature Reviews Endocrinology, 8, 228-236. https://doi.org/10.1038/nrendo.2011.183

[2] (2004) WHO and IDF Diabetes Action Now: An Initiative of the World Health Organization and the International Diabetes Federation. WHO, Switzerland.

[3] Weber, M.B. and Narayan, K.M. (2008) Diabetes Prevention Should Be a Public-Health Priority. Lancet, 371, 473-474. https://doi.org/10.1016/S0140-6736(08)60233-0

[4] Bellamy, L., Casas, J.P., Hingorani, A.D. and Williams, D. (2009) Type 2 Diabetes Mellitus after Gestational Diabetes: A Systematic Review and Meta-Analysis. Lancet, 373, 1773-1779. https://doi.org/10.1016/S0140-6736(09)60731-5

[5] O’Sullivan, J.B. (1978) Gestational Diabetes: Factors Influencing Rate of Subsequent Diabetes. In: Sutherland, H.W. and Stowers, J.M., Eds., Carbohydrate Metabolism in Pregnancy and the Newborn, Springer-Verlag, New York, 429.

[6] O’Sullivan, J.B. (1984) Subsequent Morbidity Gestational Diabetic Women. In: Sutherland, H.W. and Stowers, J.M., Eds., Carbohydrate Metabolism in Pregnancy and the Newborn, Churchill, Livingstone, 174.

[7] International Association of Diabetes and Pregnancy Study Groups. (2010) Recommendations on the Diagnosis and Classification of Hyperglycemia in Pregnancy. Diabetes Care, 33, 676-682. https://doi.org/10.2337/dc09-1848

[8] Seino, Y., Nanjo, K., Tajima, N., Kadowaki, T., Kashiwagi, A., Araki, E., Ito, C., Inagaki, N., Iwamoto, Y., Kasuga, M., Hanafusa, T., Haneda, M. and Ueki, K. (2012) Report of the Committee on the Classification and Diagnostic Criteria of Diabetes Mellitus (Revision for International Harmonization of HbA1c in Japan). Journal of the Japan Diabetes Society, 55, 485-504.

[9] Satoh, A., Menzawa, K., Lee, S., Hatakeyama, A. and Sasaki, H. (2007) Dietary Guidance for Obese Children and Their Families Using a Model Nutritional Balance Chart. Japan Journal of Nursing Science, 4, 95-102. https://doi.org/10.1111/j.1742-7924.2007.00077.x

[10] Japan Ministry of Health, Labor and Welfare. (2015) Japanese Meal Intake Standard. 2015 Edition.

[11] Japan Diabetes Society. (1998) Food Exchange Table for Diabetic Mellitus Diet Therapy. 5th Edition.

[12] World Medical Association. The International Response to Helsinki: The WMA's Declaration of Helsinki on Ethical Principles for Medical Research Involving $\mathrm{Hu}-$ man Subjects, as Adopted by the 64th WMA General Assembly, Fortaleza, Brazil, October 2013. https://www.wma.net/en/30publications/10policies/b3/index.html

[13] Schoenaker, D.A., Mishra, G.D., Callaway, L.K. and Soedamah-Muthu, S.S. (2016) The Role of Energy, Nutrients, Foods, and Dietary Patterns in the Development of Gestational Mellitus: A Systematic Review of Observational Studies. Diabetes Care, 39, 16-23. https://doi.org/10.2337/dc15-0540

[14] Maureen, A.A., Charies, M., Venny, N. and Yeri, K. (2016) Retrospective Cohort Study on Risk Factors for Development of Gestational Diabetes among Mothers At- 
tending Antenatal Clinics in Nairobi Country. Pan African Medical Journal, 24, 155.

[15] Radesky, J.S., Oken, E., Rifas-Shiman, S.L., Kleinman, K.P., Rich-Edwards, J.W. and Gillman, M.W. (2008) Diet during Early Pregnancy and Development of Gestational Diabetes. Paediatric and Perinatal Epidemiology, 22, 47-59. https://doi.org/10.1111/j.1365-3016.2007.00899.x

[16] Syngelaki, A., Pastides, A., Kotecha, R., Wright, A., Akolekar, R. and Nicolaides, K.H. (2015) First-Trimester Screening for Gestational Diabetes Mellitus Based on Maternal Characteristics and History. Fetal Diagnosis and Therapy, 38, 14-21. https://doi.org/10.1159/000369970

[17] Morisset, A.S., Tchermof, A., Dube, M.C., Veillette, J., Weisnagel, S.J. and Robitaille, J. (2011) Weight Gain Measures in Women with Gestational Diabetes Mellitus. L Womens Health (Larchmt), 20, 375-380. https://doi.org/10.1089/jwh.2010.2252

[18] Tobias, D.K., Zhang, C., van Dam, R.M., Bowers, K. and Hu, F.B. (2011) Physical Activity before and during Pregnancy and Risk of Gestational Diabetes Mellitus: A Meta-Analysis. Diabetes Care, 34, 223-229. https://doi.org/10.2337/dc10-1368

[19] Chortatos, A., Haugen, M., Iversen, P.O., Vikanes, A., Manus, P. and Veierod, M.B. (2013) Nausea and Vomiting in Pregnancy: Associations with Maternal Gestational Diet and Lifestyle Factors in the Norwegian Mother and Child Cohort Study. BJOG, 120, 1642-1653.

[20] Zhanc, C., Liu, S., Solomon, C.G. and Hu, F.B. (2006) Dietary Fiber Intake, Diatary Glycemic Load, and the Risk for Gestational Diabetes Mellites. Daubers Care, 29, 2223-2230. https://doi.org/10.2337/dc06-0266

[21] Moreno-Castilla, C., Mauricio, D. and Hermandez, M. (2016) Role of Medical Nutrition Therapy in the Management of Gestational Diabetes Mellitus. Current Diabetes Reports, 16, 22. https://doi.org/10.1007/s11892-016-0717-7

[22] Schwingshackl, L., Hoffmaa, G., Lampusi, A.M., Knippel, S., Iqbal, K., Schwedhelm, C., Bechthold, A., Schlesinger, S. and Boeing, H. (2017) Food Groups and Risk of Type 2 Diabetes Mellitus: A Systematic Review and Meta-Analysis of Prospective Studies. European Journal of Epidemiology, 32, 363-375. https://doi.org/10.1007/s10654-017-0246-y

[23] Khan, T.A. and Sievenpiper, J.L. (2016) Controversies about Sugars: Result from Systematic Reviews and Meta-Analyses on Obesity, Cardiometabolic Disease and Diabetes. European Journal of Nutrition, 55, 25-43.

[24] Thagaard, I.N., Krebs, L., Holm, J.C., Lange, T., Larsen, T. and Christiansen, M. (2017) Adiponectin and Leptin as First Trimester Markers for Gestational Diabetes Mellitus: A Cohort Study. Clinical Chemistry and Laboratory Medicine, 55, 1805-1812. https://doi.org/10.1515/cclm-2017-0427

[25] Mullaney, L., O’Higgins, A.C., Cawley, S., Doolan, A., McCartney, D. and Turner, M.J. (2015) An Estimation of Periconceptional Under-Reporting of Dietary Energy Intake. Journal of Public Health, 37, 728-736. https://doi.org/10.1093/pubmed/fdu086

[26] Serci, I. (2008) Diabetes in Pregnancy-Dietary Management. The Practising Midwife, 11, 48-49. 